Relatos de Experiência 



\section{0 dia em que a 'Cumade Fulozinha' tomou conta da sala de aula ou Cultura popular, literatura infantil e ensino}

A na C ristina M arinho Lúcio*

R esumo: A presento neste texto, um relato de experiência com a cultura popular ea literatura infantil em três escolas de ensino básico do município deJ oão Pessoa. 0 projeto aconteceu durante os anos de 2002, 2003 e 2005. N esse período, constatei o crescente interesse da comunidade escolar em levar para o espaço da sala de aula a riqueza e a diversidade das manifestações da cultura popular, al ém de textos da literatura infantil que dialogam com a tradição oral. Assumi como postura metodológica, durante todo o trabal ho, o respeito à diversidade cultural e aos sentidos que os artistas populares imprimem ao seu fazer e ainda o reconhecimento da cultura popular como uma prática do presente, que não precisa ser resgatada nem defendida por pesquisadores, agentes culturais ou educadores, e sim reconhecida e respeitada. A dotei como referencial teórico, autorescomo Gramsci (1968), O rtiz (1985), Satriani (1986), Fernandes (2003), Soares (1999) e Candau (2002).

Palavras-chave: Cultura popular, E ducação básica, L iteratura infantil, Ensino de literatura.

A bstract: Along our text we present a report of a research on popular cultureand children'sliterature developed in threeschools of J oão Pessoa at the elementary level. The project took place in

Professora do D epartamento de L etras Clássicas e Vernáculas e do Programa de PósGraduação da UFPB. E-mail: anamanho@uol.com.br 
2002, 2003 and 2005. A long our research we observed a growing interest of theschool community in bringing to classroom all the richness and diversity of popular culture manifestations, besides several stories for children that establish dialogue with the oral tradition. O ur methodological attitude along this research was based on respect to cultural diversity and to the meaning popular artists attach to their work, besides the recognition of popular culture as a practice from the present, which does not need to be rescued nor defended by researchers, cultural agents or educators, but simply be request to be recognized and respected. G ramsci (1969), O rtiz (1985), Fernandes (2003), Soares (1999) eC andau (2002) are taken as theoretical framework.

Keywords: Popular culture, Elementary level, Children'sliterature.

N os últimos dez anos, venho me dedicando ao estudo da cultura popular na Paraíba, com especial atenção para as histórias de vida de cantadores e narradores, e também para as novas (e antigas) formas de produção, circulação e recepção de folhetos de cordel. O contato com cantadores, narradores, repentistas e poetas, dançadores e artesãos, ao longo desses anos, associado às aulas de literatura infantil, no curso de Pedagogia, conduziume para a realização de um projeto de extensão envolvendo cultura popular e ensino, desenvolvido em três escolas municipais de ensino fundamental do município de João Pessoa. Durante os anos de 2002, 2003 e 2005, realizei atividades nas escolas Padre Bartolomeu de Gusmão, Fenelon Câmara e D om M arcelo CarvaIheira. ${ }^{1}$ Fui constatando, durante as três versões do projeto, o

1 O projeto Cultura popular na escola teve o apoio da Prac-Coex-U FPB. Os alunos envolvidos nas atividades receberam uma bolsa, durante seis meses de cada ano. Também contamos com o apoio da Prefeitura M unicipal de J oão Pessoa, através da FU N JOPE, para a realização do Auto de $\mathrm{N}$ atal, na escola D om M arcelo. Participaram do projeto, como bolsistas e voluntários, Paulo Anchieta Cunha, Gabriela Buonfiglio, Erlaine da Silva, D anielle Ventura de Lima e Clécio Albuquerque da Silva. 
crescente interesse da comunidade escolar em levar para o espaço da sala de aula a riqueza e a diversidade das manifestações da cultura popular, numa prática de reconhecimento e respeito.

0 trabalho com a cultura popular na escola abriu caminhos para que desenvolvêssemos projetos de pesquisa envolvendo alunos da graduação e da pós-graduação em L etras. O s projetos estão voltados para a busca de metodologias de análise e leitura de obras da literatura brasileira que dialogam com a cultura popular. Busquei, além da análise das obras, propor metodologias de trabalho com a cultura popular em sala de aula.

D urante todas as atividades que realizei com alunos da graduação e da pós-graduação, além dos professores do ensino fundamental, busquei deixar clara a minha postura diante da cultura popular. Assumi o respeito à diversidade cultural e aos sentidos que os artistas populares imprimem ao seu fazer e ainda o reconhecimento da cultura popular como uma prática do presente, que não precisa ser resgatada nem defendida por pesquisadores, agentes culturais ou educadores, e sim reconhecida e respeitada. L evar narradores populares, cantadores, brincantes e artesãos para o espaço da sala de aula é uma das formas de colocar em confronto experiências e modos de vida distintos, de fazer com que alunos e professores falem sobre sua cultura, suas crenças, e não se sintam discriminados por fazer parte de um grupo social que cultiva práticas religiosas populares, acredita em superstições, em raízes e rezas que curam.

Percebi, ao longo desses anos, que é possível trazer para o centro das discussões o caráter político da cultura popular, que se coloca, como ensina Gramsci (1968, p. 65), como uma cultura de resistência e ainda como "concepção do mundo e da vida", oposta às concepções da cultura hegemônica. Assumir essa postura diante da cultura popular significa não subtrair sua concepção de mundo particular, quando levada ao espaço da escola. A cultura popular, para muitos educadores e agentes culturais, ainda está associada à cultura do menos, aos "erros de gramática" presentes nos poemas e na fala dos narradores, ao pitoresco, ao exótico. 
A cultura popular "envergonha"; poucos se identificam com práticas religiosas como o candomblé, a umbanda, poucos querem ser vistos dançando $\mathrm{coco}$, ciranda, maracatu. A não ser quando essas práticas aparecem "higienizadas" pelos meios de comunicação e pela própria escola: desaparecem os sujeitos (geralmente, pretos, pobres e iletrados) e são evidenciados os produtos.

As etapas para a realização do projeto de extensão nas escolas foram as seguintes: reconhecimento da comunidade escolar; exibição de vídeos produzidos pelo L aboratório de Estudos da O ralidade - LEO ${ }^{2}$ - sobre aspectos da cultura popular na Paraíba (cocos, cirandas, contos, depoimentos de artesãos e artistas, aspectos da religião afro-brasileira); leitura de folhetos de cordel; leitura de textos da literatura infantil que dialogam com a cultura popular; pesquisa na comunidade para identificação de artistas populares; realização de encontros entre os artistas do bairro e a comunidade escolar.

$\mathrm{N}$ os primeiros encontros, quando eu indagava quem, entre meninos e meninas, alunos e professores do ensino fundamental da escola Bartolomeu de Gusmão, tinha, na família, um cantador de repentes e cocos ou um contador de histórias, eu obtinha 0 silêncio como resposta. Ao final do primeiro mês, comecei a perceber certa mudança na atitude de alguns jovens. U m ou outro perguntava se as histórias da 'C umade Fulozinha', os pontos cantados de umbanda, faziam parte do folclore. Percebi que os alunos não identificavam como folclore as histórias que conheciam. Folclore estava nos livros, nas histórias de saci-pererê e iara, na relação de comidas típicas de cada região do Brasil, presente nos livros didáticos e tantas vezes recortada e colada nos murais durante a "Semana do Folclore".

N o segundo mês de encontros, o número de alunos que assistia aos vídeos produzidos pelo LEO, que lia folhetos de cordel e ouvia canções, estava reduzido à metade. U m dia, resolvi

Laboratório de pesquisa associado aos programas de pós-graduação em L etras e Sociologia da UFPB. 
visitar a escola no período da manhã, para conhecer os alunos e professores das fases iniciais do ensino fundamental. Q ual não foi a minha surpresa ao ouvir de uma professora que as aulas, no dia anterior, foram interrompidas, porque um tumulto havia se instalado nas dependências da escola: um aluno afirmava ter visto a 'Cumade Fulozinha' no banheiro e as crianças, assustadas, não quiseram mais voltar às salas de aula.

Grande parte dos alunos da escola Bartolomeu de G usmão mora nos limites da $M$ ata do Buraquinho, reserva de $M$ ata Atlântica que hoje faz parte do J ardim Botânico da cidade. Essa proximidade imprime novos sentidos às histórias da 'Cumade Fulozinha', entidade protetora das matas, aproximando-as do cotidiano dos alunos e familiares. Eu soube depois, que uma das alunas guarda uma flor deixada pela 'C umade' na sua rede, quando ainda era um bebê. 'Fulozinha' havia desistido de levá-la para a mata e deixou de presente a flor e a incumbência de sempre render homenagens.

A experiência me levou a refletir sobre a prática em sala de aula, sobre o modo como eu apresentava as narrativas aos alunos. 0 que para os pesquisadores era literatura oral, cultura popular, para os alunos era uma prática cotidiana, era um "fazer dentro da vida." 'F 'Fulozinha' não era mito nem história, era aquela mulher de cabelos longos que assustava as crianças, que fazia tranças nas crinas dos cavalos e dava pisas nos cachorros, desorientava os caçadores que entravam na mata sem a sua permissão e que, vendo seu espaço ocupado por casas e ruas asfaltadas, aparecia no banheiro da escola para 'marcar terreno'.

A pós essa experiência, sempre que converso com alunos e professores sobre narrativas orais, procuro contar histórias sem classificá-las. Conto sobre a minha experiência como ouvinte das histórias de Trancoso, narradas por Goba, vendedor de cocadas (e fantasias) que conheci quando criança. Leio folhetos e vivencio, a cada encontro, o contentamento e a alegria em saber das estripulias de J oão G rilo ou dos amores sofridos de A Izira.

3 Expressão utilizada por LIM A (1995) para definir o conto popular. 
Alguns professores das escolas nas quais desenvolvi atividades demonstraram resistência em reconhecerem-se como fazendo parte da cultura popular. É mais cômodo ser apreciador, admirador, interessado em resgatar a tradição. M uitas vezes, no espaço escolar, a cultura popular surge associada ao atraso, à desinformação e ao preconceito. Cantos como o coco e a ciranda, na voz de Chico César ou Chico Science, são bem aceitos. Porém, quando cantados por Seu M anoel, do Bairro dos N ovais, em João Pessoa ou D ona Lenita, de Gurugi, no município do Conde, provocam riso e atitudes preconceituosas, observadas nos comentários feitos pelos alunos que evidenciam a cor da pele dos cantadores, o jeito de falar, o modo de se vestir.

0 respeito à cultura e aos valores dos alunos está no centro das discussões e embala o debate sobre o multiculturalismo nas escolas. Sobre esse aspecto, me deterei um pouco mais. Peter M acL aren e J ames Banks (apud CAN DAU , 2002), pesquisadores americanos que desenvolveram estudos sobre o fracasso escolar de alunos oriundos das camadas populares, identificaram dois diferentes discursos que justificam essa situação. 0 primeiro "parte do pressuposto de que o fracasso desses alunos está motivado pela cultura em que foram socializados, que não Ihes favoreceu experiências fundamentais para o bom desempenho escolar." (M ACLAREN apud CANDAU, 2002, p. 88). A solução estaria na compensação das deficiências. $\mathrm{H}$ á um reconhecimento da diversidade cultural, mas, ao mesmo tempo, uma desvalorização de determinadas culturas (cabe aos educadores uma "função de compensação cultural que termina por negar a diferença". 0 segundo toma como princípio a diversidade de linguagens, valores, símbolos e estilos das diferentes culturas.

"O queprecisaser mudado não éacultura do aluno, mas a cultura da escola, queéconstituída com base em um único modelo cultural, o hegemônico, apresentando um caráter monocultural" (CAN D AU , 2002, p. 132-133).

Para tomar o segundo modelo como exemplo, é importante ter como ponto de partida (e de chegada) uma concepção de cultura como "um processo em contínua construção, 
desconstrução e reconstrução, no jogo das relações sociais presentes nas sociedades. N este sentido, a cultura não é, está sendo a cada momento". N a escola, o entendimento do multiculturalismo passa, muitas vezes, apenas pela "inclusão de contribuições de diferentes grupos étnicos no currículo, ou a redução do preconceito ou a celebração de festas relacionadas às diferenças culturais" (CAN DAU , p. 134-135). O folclore parece ocupar esse espaço na vida escolar.

N ão raro, lemos textos e ouvimos discursos sobre o "valor educativo do folclore". E aí começam as discussões e questionamentos: o folclore deve ser incorporado a alguma disciplina que tenha como temática a questão cultural? D eve ser utilizado de forma interdisciplinar ou é necessário criar uma disciplina específica para dar conta do seu conteúdo e formas? Interessame, neste ponto, apresentar algumas ideias presentes num texto escrito em 1976, fortemente marcado pelas discussões que envolviam o "valor educativo do folclore" naquela década: 0 folclore na escola, de M aria de L ourdes Borges R ibeiro, me fornece subsídios para discutir sobre o aproveitamento do folclore e da cultura popular pela escola. Conservadas as proporções e o tempo em que o texto foi escrito, pude constatar, durante a realização do projeto de extensão, que algumas das posturas assumidas pela pesquisadora ainda fazem eco entre professores, alunos e pesquisadores da cultura popular.

L ogo no início do seu texto, a autora chama a atenção para o aproveitamento do folclore na cultura superior e cita autores como H erder, Goethe, Georg Sand e compositores como Chopin. E afirma:

O Folclore éum mundo, uma cultura. Portanto, tem, como disse, zonas de luz e de sombra, elementos de inspiração artística, estórias e contos cheios devaloreshumanos, provérbios que valem como síntese defilosofia, criação de tipos argutose sutis paravencer os violentos e brutais, melodias e ritmos, poesia, pintura, escultura, técnicas valiosas, tudo queo empirismo do homem rudimentar pôdeadivinhar no mundo que o cerca, com a experiência que $D$ eus Ihe deu. $M$ as, por igual, um acervo de erros, cuja persistência resultaria prejudicial efunesta. Portanto, a primeira condição quese exigedo professor, ésagacidade eagudeza, éfazer o aproveitamento apenas 
do que for útil. Enquanto os folcloristas pesquisam o fato folclórico em essência, dentro desua funcionalidade no meio do grupo onde se produz e se desenvolve, o professor selecionará o que deva utilizar. (RIBEIR O, 1976, p. 4-5)

Percebo, nesse trecho, duas situações interessantes: o folclore tem o seu valor, mas dele deve ser subtraído "um acervo de erros, cuja persistência resultaria prejudicial e funesta." N ão há um único exemplo desses erros no texto, mas a afirmação seguinte me fornece um caminho para descobrir: cabe ao folclorista, e não ao professor, identificar a funcionalidade do fato folclórico "no meio do grupo onde se produz e se desenvolve". Em outras palavras, quando retirado do seu contexto de produção, quando retiradas as vozes dos narradores e poetas, as experiências dos sujeitos que fazem a cultura, o produto final, higienizado, poderá ser aproveitado pela escola. M ais adiante, a autora menciona a contribuição do folclore para os educandos: "favorecer a compreensão, desenvolver a memória, incentivar a fantasia ou oferecer centro de interesse ou de relação concernente ao que se está ensinando." (RIBEIR O, 1976, p. 5) Vejamos mais uma citação do texto:

Como distinguir entre o aproveitável eo indesejável? I mpossível determinar. Cada professor, em cada circunstância, lugar e hipótese, procurará, com perspicácia e finura, resolver o problema, no campo, sobretudo, onde a criança vê e ouve em casa o que o professor tem que proibir. Aliás, 0 Folcloreestá sendo considerado como método didático enenhum método pode ser aplicado em absoluto, sem levar em conta condições de meio e aluno. As possíveis dificuldades poderão ser vencidas, partindo-se do princípio de queo objetivo da utilização do Folcloreestáem ligar o homem à terra e em aproveitar todos os fatores que, vindos do povo, podem servir para melhor conhecêlo ou torná-lo conhecido.(RIBEIR O, 1976, p. 8)

Há, nesse recorte, três aspectos que merecem atenção: "a criança vê e ouve em casa o que o professor tem que proibir"; o folclore é considerado como um método didático; e, por fim, o folclore na escola tem como objetivo ligar o homem à terra. $\mathrm{No}$ primeiro ponto, há uma recusa explícita em reconhecer e respeitar a experiência e a cultura do aluno, o que ele leva de casa para 
a escola. A escola não aceita a cultura do aluno e, na maioria das vezes, não consegue oferecer a esse mesmo aluno, em geral pertencente às classes populares, os saberes necessários para que ele consiga inserir-se no mundo da cultura hegemônica (M ACLAREN; BANKS apud CANDAU, 2002).

$M$ inha experiência de trabalho na escola Dom Marcelo, localizada num bairro afastado do centro da cidade, local para onde foram removidas as famílias que viviam no Lixão do R óger, ${ }^{4}$ aponta para o lado perverso da educação no nosso país. D urante todo um semestre, procurei, junto aos alunos e aos seus familiares, ouvir histórias tradicionais, cantos, cantigas, brincadeiras, canções. Fui, ao longo do tempo, percebendo que, com exceção das famílias que migraram do interior do estado, os alunos só conheciam histórias veiculadas por programas televisivos. Os poucos que conseguiam contar histórias eram aqueles que faziam parte de algum grupo evangélico e, por essa razão, conheciam narrativas do A ntigo Testamento. A escola possui um acervo considerável de obras da literatura universal, distribuídas pelo MEC, mas poucos alunos leem esses livros. Constatei que os professores também não conhecem os textos e a sala de leitura 'serve' para 'tirar' os alunos da sala de aula e aproveitar esse tempo livre para resolver questões pessoais ou burocráticas. Encontrei uma comunidade cada vez mais pobre de experiências e uma escola que, além de não reconhecer a experiência dos alunos como válida, não fornece o mínimo de conhecimentos para a vida, não preenche a necessidade de fantasia dos alunos através da literatura. O s livros estão lá, o espaço para leitura também, faltam os leitores.

O segundo ponto encaminha-me para as discussões em torno do folclore visto como um método didático. Q uando comenta sobre os contos populares, M aria de L ourdes R ibeiro alerta para o aproveitamento dessas narrativas pelo professor, que

4 Área localizada no centro da cidade, aterrada no ano de 2004. Os moradores da região, que viviam da coleta do lixo, foram deslocados para o outro lado da cidade, para um condomínio de apartamentos nunca concluído. 
poderá entender o "temperamento da criança, pelas suas reações ao ler ou ouvir contar uma história" (1976, p. 9). O folclore, como método, serve para entender a "alma do povo", como pensavam os folcloristas e românticos do século XIX, como pensam ainda hoje alguns professores e pesquisadores.

N esse ponto, volto aos questionamentos sobre o espaço que deve ocupar o folclore na escola. A credito que não é necessário criar disciplinas específicas para trabalhar com os textos populares. Ao invés de pensar no "aproveitamento" do folclore pelo professor, eu poderia pensar numa sensibilização de toda a comunidade escolar para as experiências e práticas culturais do povo. $\mathrm{N}$ ão precisamos de semanas dedicadas ao folclore: o professor pode trabal har com seus alunos textos literários, canções, depoimentos de artistas e artesãos em sala de aula, experiência possível e enriquecedora, comprovada ao longo dos três anos de realização do projeto.

Por último, R ibeiro (1976) aponta como um dos objetivos de trabalhar o folclore na escola reestabelecer a ligação do homem com a terra. A autora chega a sugerir que o professor priorize o trabalho com o artesanato, uma das formas de garantir sustento aos mais jovens e sua permanência no campo. 0 caráter pragmático que assume o trabal ho com o folclore na escola é o mesmo que encontramos no trabal ho com a literatura. 0 mais grave é que, com relação aos textos tradicionais, à cultura do povo, esse pragmatismo se volta para o mercado de trabalho: a educação voltada para as classes populares deve ser aquela que encaminha para o mercado de trabalho. E qual seria o lugar da literatura popular na escola?

\section{Quem nunca atirou o pau do gato? ou Novos paradigmas educacionais e a literatura popular}

Minha experiência de trabalho com a literatura popular em sala de aula revelou a permanência de um modo de ver as 
manifestações da cultura como resquícios de práticas antigas ou primitivas, estágios a serem superados, num continuum que tem como fim (e finalidade) a cultura erudita.

O estabelecimento de diferenças entre literatura erudita e popular faz parte da prática do professor em sala de aula. 0 problema é que, muitas vezes, o estudo comparativo (presente nos livros didáticos, nos exemplos que o professor utiliza em sala de aula, nas análises de obras que se aproximam da literatura oral ou refratam a visão de mundo de camadas populares), resulta em práticas que "diminuem" a literatura popular, marcando apenas aspectos que evidenciam um distanciamento da norma culta da língua e uma visão de mundo considerada atrasada, provinciana.

O trabalho com a literatura de cordel na sala de aula não é mais uma novidade. O s professores de língua portuguesa, alguns até embalados pela presença de poetas como Patativa do A ssaré, em programas do vestibular, vêm realizando atividades com a poesia popular na sala de aula. A escola tem se tornado um espaço para a divulgação da literatura de folhetos e os poetas e vendedores, como não poderia deixar de ser, estão muito interessados nesse novo mercado. 0 que me chama a atenção é que começo a perceber mudanças na postura de alguns poetas. Tudo que passa pela escola corre o risco da didatização e quando se trata da escolarização da leitura literária o problema se torna mais sério (SOARES, 1999).

A leitura de alguns folhetos, publicados nos últimos quatro anos, aponta para a influência desse novo público leitor. O bservo mudanças nos versos e nas estruturas de produção. As mudanças são observadas, inicialmente, nas contracapas dos folhetos. Vejamos alguns exemplos:

Professores, utilizem o cordel em sala de aula e surpreendam-se com os resultados obtidos! Para criar no aluno o hábito de leitura, o melhor artifício é oferecer-Ihe um cordel! (CORDELARIA POETA M ANUEL MONTEIRO)

Cordel: expressão cultural do nosso povo. 0 cordel pode ser uma excelenteferramenta paradidática na sala de aula, não só pela sua importância 
cultural e rica estrutura de ritmo, métrica e rima, como também para destacar e debater as formas populares de falar e pensar, reatando definitivamente os laços do aluno com a verdadeira cultura brasileira. (BAR$\mathrm{ROS}, \mathrm{s} / \mathrm{d}$.)

N esses textos, observamos o caráter pragmático que assume a literatura em contexto escolar (o cordel transforma-se em ferramenta paradidática), além de uma visão da cultura popular como o elo perdido, o caminho que vai levar o aluno a reatar os laços com a "verdadeira cultura brasileira".

N os últimos quatro anos, venho observando o uso que alguns professores fazem do folheto em sua prática de sala de aula. ${ }^{5}$ O s exemplos são variados: há aqueles que acreditam que é necessário criar uma disciplina específica para trabal har a literatura de cordel na sala de aula, em que os alunos aprenderiam as estruturas do cordel, as rimas e a métrica, conheceriam os folhetos considerados clássicos e poderia até surgir um novo Leandro Gomes de Barros. Sempre ouvi com preocupação o entusiasmo desses professores. A literatura popular não precisa de uma disciplina específica. Os poemas de Patativa do Assaré podem ser lidos e apreciados do mesmo modo como são lidos os poemas de $\mathrm{M}$ anuel Bandeira e Fernando Pessoa, como foi possível observar nas minhas experiências em salas de aula do ensino médio.

A Prefeitura de Campina Grande, na Paraíba, desenvolveu um projeto, no ano de 2004, voltado para a distribuição de uma coleção de folhetos para cada escola do município. Foram 16 títulos, entre produções consideradas clássicas, como Viagem a São Saruê, de M anuel Camilo, e folhetos recentes de poetas como $\mathrm{M}$ anoel $\mathrm{M}$ onteiro. A iniciativa da prefeitura possibilitou ao professor ter em mãos um rico material para trabalho com seus alunos. M as um aspecto me chamou a atenção: ao invés de comprar os folhetos, disponíveis em folhetarias e cordelarias, em cidades como Patos e Campina Grande, a prefeitura optou por reproduzir os

As experiências com o cordel em sala de aula são compartilhadas com H élder Pinheiro, resultado de uma parceria iniciada quando publicamos o livro $\mathrm{C}$ ordel na sala de aula. São Paulo: Duas Cidades, 2001. 
versos na gráfica do município. E como fica o direito autoral nesse caso? O s poetas vivos, ou os familiares dos que já morreram, foram consultados sobre a reprodução dos seus textos?

0 poeta e vendedor de folhetos $M$ anuel M onteiro participou desse projeto não apenas com seus folhetos, mas também com a sua presença em sala de aula. D urante as visitas às escolas, $M$ anuel $M$ onteiro comentava sobre a literatura de cordel e lia versos seus e de outros poetas. $\mathrm{N}$ o folheto "L ampião... era o cavalo do tempo atrás da besta da vida", M onteiro desenvolve um tema forte da literatura de cordel, além de reescrever algumas estrofes d' "A chegada de L ampião no inferno", de J osé Pacheco, folheto bastante conhecido entre os leitores e ouvintes de cordel. N essa publicação, os versos de Pacheco recebem uma nova roupagem. 0 poeta substitui algumas palavras dos versos, como nos exemplos a seguir: ${ }^{6}$

\begin{tabular}{|c|c|}
\hline Morreram 10 negros velhos & Morreram 10 pretos velhos \\
\hline Quem é você cavaleiro? & Quem é você cavalheiro \\
\hline Eu não sou seu pariceiro & Eu não sou seu pareceiro \\
\hline Eu viro tudo asavesso & Eu viro ao avesso \\
\hline Convide aí a negrada & Recrute aí a cambada \\
\hline Pra virem os negros que tem & Pra virem os diabos que tem \\
\hline E reuniu-se a negrada & Reuniu-se a cabroeira \\
\hline
\end{tabular}

Subtrai estrofes inteiras, como a seguinte:

Então essetal vigia

Q ue trabalha no portão

D á pisa que voa cinza

$\mathrm{N}$ ão procura distinção

6 Na primeira coluna, transcrevo os versos do folheto "A chegada de Lampião no inferno", de José Pacheco. 
0 negro escreveu não leu

A macaíba comeu

Lá não se usa perdão

R eescreve outras:

\begin{tabular}{|c|c|}
\hline Leitores vou terminar & Também não vou falar mais \\
\hline Tratando de Lampião & Do inferno e Lampião \\
\hline Muito embora que não posso & E mesmo não tendo ordem \\
\hline Vos dar a solução & Vou dar uma informação \\
\hline No inferno não ficou & Se o cão não o aceitou \\
\hline No céu também não chegou & No céu é que não ficou \\
\hline Por certo está no sertão & Por certo está no sertão \\
\hline Quem duvidar nessa história & Quem duvidar nessa história \\
\hline Pensar que não foi assim & Pensar que não foi assim \\
\hline Querer zombar do meu sério & Não acreditar em Zé \\
\hline Não acreditando em mim & Desacreditar em mim. É fácil \\
\hline Vá comprar papel moderno & Compre lápis e caderno \\
\hline Escreva para o inferno & Escreva para o inferno \\
\hline Mande saber de Caim & Mande saber de Caim \\
\hline
\end{tabular}

Existe uma preocupação com a correção da linguagem, além de uma adequação ao "politicamente correto". Chamar todos os diabos de "negrada" ou "tropa preta" pode parecer, aos olhos do poeta e de alguns professores, um reforço ao preconceito racial. Q uero acreditar que o diálogo com (e a partir) do texto literário é sempre uma experiência enriquecedora. $\mathrm{N}$ ada que um debate em sala de aula, bem conduzido pelo professor, não resolva. 0 poeta parece esquecer que o texto literário respira 
seu tempo, existe na melodia, no ritmo, na voz e nas palavras do autor. M anuel M onteiro chega a fazer um julgamento do herói, quando substitui o verso "no céu também não chegou" por "no céu é que não ficou". L ampião, como qualquer outro bandidoherói, teria também um lugar no céu. $\mathrm{N}$ a literatura de folhetos, muitos são os exemplos de personagens que saem do inferno para o céu e vice-versa. 0 trânsito entre esses do is espaços reproduz a visão de mundo de uma camada da população que reinventa e recria formas de existir, mesmo depois da morte. A história de José Pacheco está escrita em "papel moderno" e na memória de muitos leitores e ouvintes de folhetos. Os versos de $\mathrm{M}$ anuel Monteiro talvez fiquem apenas nas "folhas do caderno".

Aos meninos e meninas, interessa muito mais ouvir e ler as histórias de João Grilo, Cancão de Fogo, as pelejas do C ego Aderaldo, e também os novos folhetos que tratam da "Chegada de D om H élder no céu" e as inúmeras pelejas entre poetas, algumas delas travadas na Internet. Cabe aos professores tornar visível a literatura de folhetos na escola, fazer com que os alunos reconheçam essa produção literária e possam se reconhecer nos textos lidos ou ouvidos.

$\mathrm{N}$ as discussões em sala de aula, nas atividades do projeto de extensão, nos cursos de formação de professores, sempre me deparo com alunos que relatam suas primeiras experiências com a ficção, com a poesia, através do contato com contadores de histórias e poetas repentistas. Muitos deles dizem que os pais aprenderam a ler através do folheto. Q uando chegam à escola, essas experiências são postas de lado e a literatura assume um lugar distante da vida, próxima do dever, da lição, do ensino de gramática.

O trabalho com textos como "A chegada de L ampião no inferno" e canções tradicionais como "Atirei o pau no gato", na sala de aula, sempre gera um debate entre os professores: escuto comentários sobre a existência de certas atitudes de desrespeito à natureza, posturas que reforçam o preconceito racial, principalmente no Brasil, onde, durante muito tempo, o discurso da 
igualdade racial, da cordialidade, orientou práticas e posturas pedagógicas.

D urante toda a minha infância, brinquei de "Atirei o pau no gato", na rua e no pátio da escola. O utro dia, soube que nas escolas e nos livros didáticos a letra da canção não é mais a mesma. Agora, as crianças cantam " $N$ ão atire o pau no gato que ele ébonzinho"[...]. Lembro de quealguns dos meus amigos deinfância gostavam de 'judiar' dos gatos: deixar cair de lugares altos, 'guardar' na geladeira, até cortar o rabo de alguns. "M enino não presta!" M as a música do gato era mesmo boa pra fazer a meninada "rodar-rodar-rodar" e cair no chão no miau final. D epois, todos voltavam para a sala de aula, suados e cansados, e conseguiam o mínimo de concentração para entender matemática. Se é que vejo um fator útil no uso do folclore na escola, aí está ele (não precisam levar muito a sério esse último comentário).

$\mathrm{N}$ esse ponto, eu me aproximo de outro aspecto trabalhado nos projetos que desenvolvo: a relação íntima entre textos da tradição popular, especialmente os contos, e a literatura infantil.

\section{A mulher que gastou sete sapatos de ferro até encontrar um marido ou Diálogos entre literatura popular e literatura infantil}

Os vários estudos sobre a natureza da literatura infantil apontam para dois aspectos importantes: a preocupação com o caráter didático e a relação com a cultura popular. Ao longo da história da literatura infantil brasileira, essa relação vai adquirindo aspectos diferenciados: ora há um interesse apenas pelos motivos e temas, ora esse interesse se volta para a linguagem, para a manutenção de valores da tradiçãoo (família, comunidade, respeito aos mais velhos...), ou ainda, na maior parte dos casos, para o que muitos denominam "encontro com as nossas raízes". O exemplo mais evidente dessa relação com a tradição popular 
pode ser encontrado na coleção de textos de Charles Perrault, considerado um dos primeiros autores do gênero. $A$ análise dos contos de Perrault aponta para a necessidade de estabelecer relações com disciplinas como a psicanálise, a sociologia e a história, além dos estudos literários. Sabemos que as adaptações dos contos que circulavam em meio popular, feitas pelo autor, atendiam aos interesses da burguesia, que passava a considerar a criança um ser em formação. M esmo com as modificações feitas nas narrativas, permanece a visão de mundo das classes populares, algumas vezes identificada com aspectos revolucionários, outras com a violência, embora filtrada por inúmeras atualizações, adaptações, mutilações. 0 elemento maravilhoso continua respondendo às inquietações de uma classe que, completamente destituída de possibilidades de ascensão social, apela para objetos mágicos, viagens a países distantes e imaginários.

Sempre que possível, procurei, durante os cursos de capacitação para professores dos ensinos fundamental e médio, contrapor algumas análises de Bruno Betelheim (1996), que despertam enorme interesse entre os professores, presentes no livro A psicanálise dos contos de fada, buscando contextualizar essas narrativas. A leitura do livro 0 grande massacre de gatos, de Robert D arnton (1988), fornece elementos para o debate. As análises de Bettelheim são, de fato, muito boas. Tudo faz sentido: para todos os objetos mágicos e ações das personagens, há um fundo psicológico, para não dizer patológico, correspondente. Os professores, assustados com a análise do conto Chapeuzinho Vermelho, são unânimes em afirmar que as crianças continuam maraviIhadas com os episódios e as personagens, seja em versão impressa, seja nas telas do cinema, seja na voz do professor ou dos pais. A entrada do livro de Bettelheim nas escolas brasileiras, nos cursos de Pedagogia, trouxe de volta para a sala de aula os contos de fada, mas colocou uma pulga atrás da orelha dos professores. $\mathrm{N}$ a década de 1990, os contos tradicionais são mais uma vez deixados de lado, pois o lobo tem que ser protegido, as florestas não podem ser consideradas lugares escuros e perigosos, a mulher não pode gastar sete sapatos de ferro correndo atrás 
do marido, como no conto "O pássaro do Limo Verde". Ao mesmo tempo, autoras como Ana M aria M achado e Ruth Rocha, entre outras, passam a recriar as histórias tradicionais acrescentando finais inusitados, atitudes diferenciadas das personagens.

0 que ninguém pode negar é que, mesmo modificados, politicamente corretos, os contos não perdem a sua estrutura tradicional. Há sempre um objeto mágico que vai auxiliar os heróis na sua demanda, os bons são recompensados ao final, o "era uma vez" transporta leitores e ouvintes para um mundo em que tudo pode acontecer (e as crianças aprendem desde cedo o que está nesse universo da fantasia e o que está fora dele). Quanto às estruturas narrativas, os motivos estão presentes, os temas também, as personagens (de cara nova) são muitas vezes cópias invertidas das matrizes, os lugares (não mais a floresta tenebrosa, o poço escuro) conservam a mesma ambiência.

Quero finalizar esse relato de experiências, muito mais uma exposição de posturas e métodos diante da cultura popular e sua presença em contextos educacionais, comentando o que afirma Florestan Fernandes (2003), no seu texto sobre a obra de $\mathrm{M}$ ário de Andrade. Para o escritor, o estabelecimento de uma verdadeira literatura nacional passava pelo reconhecimento de uma relação de "mútua dependência" entre as artes erudita e popular. Cada vez mais, acredito que o trabalho do professor em sala de aula deve ser orientado por uma postura de reconhecimento da cultura popular e de reconhecimento dessa relação de mútua dependência de que trata Florestan Fernandes. N esse sentido, as discussões sobre o estabelecimento de disciplinas específicas para o trabalho com a cultura popular em sala de aula parecem não levar a lugar algum. D urante to do o trabalho desenvolvido com professores, alunos e funcionários das escolas, alunos e pesquisadores da U niversidade, procurei fazer com que cada um deles pensasse sobre a relação que estabelecem com a cultura. É dessa relação, da forma como cada um se aproxima dos textos, sejam eles populares ou não, que resultará o seu trabalho como professor ou pesquisador. $\mathrm{E}$ agora é só pedir permissão à 'C umade 
Fulozinha' e entrar na mata sem medo de lobo mau ou de perder sete anos da vida em busca de um casamento com final feliz.

\section{Referências}

BAR R OS, L eandro Gomesde. 0 cachorrodosmortos Recife: Tupynanquim, s/d.

BETTEL H EIM , Bruno. A psicanálisedos contos defadas São Paulo: Paz e Terra, 1996.

CAN DAU, Vera M ariaFerrão. Sociedade, cotidiano escolar ecultura(s): uma aproximação, Educaçãoesociedade, n. 79, p. 125-161. A gosto-2002.

DAR NTON, R obert. 0 grandemassacredegatos. Rio deJ aneiro: Graal, 1988.

EN GU ITA, M ariano F. A face oculta da escola: educação e trabalho no capitalismo. Porto Alegre: A rtes M édicas, 1989.

FER N AN D ES, Florestan. 0 foldoreem quetão. São Paulo: M artinsFontes, 2003.

GRAM SCI, Antonio. Literatura evida nacional. R io de Janeiro: Civilização Brasileira, 1968.

LI M A, Francisco A ssis de Sousa. C onto popular ecomunidadenarrativa. Rio de Janeiro: FU NARTE, 1985.

M CLAR EN, Peter. M ulticulturalismo crítico. São Paulo: Cortez, 1997.

O RTIZ, R enato. C ultura popular: românticos efolcloristas. São Paulo: Programa de Estudos Pós-Graduados em Ciências Sociais/ PU C, 1985.

PIN H EIR O, H élder; LÚ CIO, A na Cristina M arinho Lúcio. C ordel na sala de aula. São Paulo: D uas Cidades, 2001.

RIBEIRO, M aria de L ourdes Borges. $O$ folclore na escola. C adernos de folclore, MEC-FU N ARTE, 1976.

SATR IAN I, L uigi M . L ombardi. A ntropologia cultural eanáliseda cultura subalterna. São Paulo: H ucitec, 1986. 
SO AR ES, M agda. A escolarização da literatura infantil ejuvenil. I n: EVAN GELISTA, A racy; BR IN A, H eliana; M ACH AD O, M aria Zélia (orgs.). A escolarização da leitura literária: o jogo do livro infantil e juvenil. Belo H orizonte: A utêntica, p. 17-48, 1999. 